OPEN ACCESS

Edited by:

Lien Luong,

University of Alberta, Canada

Reviewed by:

Brandon Parker Ruehle,

University of Otago, New Zealand

Iain James Gordon,

Australian National University,

Australia

*Correspondence:

O/wyn C. Friesen

olwynfriesen@gmail.com

Specialty section:

This article was submitted to Behavioral and Evolutionary Ecology,

a section of the journal

Frontiers in Ecology and Evolution

Received: 28 November 2020

Accepted: 19 February 2021

Published: 12 March 2021

Citation:

Friesen OC and Detwiler JT (2021) Parasite-Modified Chemical Communication: Implications for Aquatic Community Dynamics.

Front. Ecol. Evol. 9:634754.

doi: 10.3389/fevo.2021.634754

\section{Parasite-Modified Chemical Communication: Implications for Aquatic Community Dynamics}

\author{
Olwyn C. Friesen* and Jillian T. Detwiler \\ Department of Biological Sciences, University of Manitoba, Winnipeg, MB, Canada
}

Chemical communication within an aquatic environment creates an intricate signaling web that provides species with information about their surroundings. Signaling molecules, like oxylipins, mediate a multitude of interactions between free-living members of a community including non-consumptive effects by predators. Parasites are another source of signaling molecules in aquatic communities and contribute directly by synthesizing them or indirectly by manipulating host chemical cues. If chemical cues of infected hosts are altered, then non-consumptive interactions between other members of the community may also be affected. Different cues from infected hosts may alter behaviors in other individuals related to foraging, competition, and defense priming. Here, we discuss how parasites could modify host chemical cues, which may have far reaching consequences for other community members and the ecosystem. We discuss how the modification of signaling molecules by parasites may also represent a mechanism for parasite-modified behavior within some systems and provide a mechanism for non-consumptive effects of parasites. Further, we propose a hostparasite system that could be used to investigate some key, unanswered questions regarding the relationship between chemical cues, parasite-modified behavior, and nonconsumptive effects. We explain how trematode-gastropod systems can be used to test whether there are alterations in the diversity and amounts of signaling molecules available, and if habitat use, immune function, and behavior of other individuals and species are affected. Finally, we argue that changes to pathway crosstalk by parasites within communities may have broad ecological implications.

Keywords: chemical communication, non-consumptive interactions, community dynamics, oxylipins, signaling web, infochemicals, volatile organic compounds, non-consumptive effects

\section{INTRODUCTION}

Species obtain important information about their surroundings through intricate signaling webs created by chemical cues (Brönmark and Hansson, 2000; van Poecke and Dicke, 2004; Vos et al., 2006). Cues can have a variety of functions including alarm cues, chemical defense, and sex pheromones, that impact the behavior and physiology of organisms receiving these signals (Kats and Dill, 1998; Kaupp et al., 2006; Fink, 2007; Pohnert et al., 2007; Kita et al., 2010). Aquatic organisms respond to minute concentrations of chemical cues within this environment (Dicke and Sabelis, 1988; Brönmark and Hansson, 2000; Vos et al., 2006). Gradual changes in chemical cue diversity and concentration throughout an ecosystem relays important information to species, 
creating a network or signaling web that can be used by community members and influence community dynamics (van Poecke and Dicke, 2004; Vos et al., 2006; Fink, 2007; Brönmark and Hansson, 2012). As a result, many interactions, such as predator avoidance, and parasite transmission are influenced by cues produced in the community (Kats and Dill, 1998; Burks and Lodge, 2002; Fink, 2007; Saha et al., 2019).

Within the aquatic community, individuals of other species may also "eavesdrop" on this communication to obtain additional information about their environment (Baldwin et al., 2006; Vos et al., 2006). If predators and parasites can perceive cues through all of the chemicals found within the aquatic system, or "ambient noise," they can take advantage of chemical crosstalk to increase depredation and transmission (Schultz and Appel, 2004; Baldwin et al., 2006; Brönmark and Hansson, 2012). For example, eavesdropping has been shown to facilitate tritrophic interactions in aquatic communities. Plants released oxylipins and other VOCs as they were being consumed by herbivores, which attracted carnivores and parasitoids that subsequently reduced herbivore performance (Martin et al., 2019; Kergunteuil et al., 2020).

Conversely, if a species is able to perceive an increased risk of predation or parasitism through the perception of cues released by other individuals, they may adopt strategies to reduce this risk (Buck et al., 2018; Weinstein et al., 2018). Indeed, chemical cues are important mediators of non-consumptive effects (NCEs) in predator-prey relationships (Ferrari et al., 2010; Hill and Weissburg, 2013). Response to predator cues leads to alterations in behavior and physiology that reduce an individual's risk of predation (Weissburg and Beauvais, 2015; Hermann and Landis, 2017). Relatively less is understood about the role of chemical cues in mediating NCEs of parasites and parasite-host interactions (Fink, 2007; Saha et al., 2019). More work is needed to determine whether parasites perceive and use crosstalk in their non-consumptive interactions with their hosts and other members of the aquatic community.

\section{OXYLIPIN CHEMICAL CUES MEDIATE COMMUNITY INTERACTIONS}

Organisms release species-specific chemical emissions, representing a unique cocktail of cues, including fatty acids, amino acids, nucleotides, and other volatile organic compounds (VOCs) (Brönmark and Hansson, 2000; Pohnert, 2002; Fink, 2007). One important group of VOCs are oxylipins, or oxygenated metabolites of fatty acids, (de Petrocellis and di Marzo, 1994; Baldwin et al., 2006) that have essential roles in normal physiology, stress, and immune response of a wide breadth of taxa, from plants to animals (Stanley-Samuelson, 1994; Fink, 2007; Caldwell, 2009; Stanley, 2014; Gabbs et al., 2015). Each oxylipin cocktail carries complex information to the receiver, with the specificity of the mixture being key to dictating the response by the receiver rather than a single oxylipin alone (Metcalf and Kogan, 1987; Wendel and Jüttner, 1996; Fink, 2007). For example, mixtures containing eicosanoids, oxylipins formed from C20:C22 fatty acids, affect the physiology of invertebrates, including the neuro- and reproductive physiology of mollusks and insect cellular defense (Stanley-Samuelson et al., 1991; Stanley-Samuelson, 1994). Eicosanoids have also been detected in a wide diversity of parasite species, including the trematodes Schistosoma mansoni and Fasciola hepatica, protozoans such as Trypanosoma brucei and Plasmodium falciparum, the cestode Spirometra erinaceieuropaei, and nematodes Brugia malayi and Dirofilaria immitis (Liu and Weller, 1992; Kubata et al., 1998, 2000; Ali et al., 1999; Noverr et al., 2003; Chaisson and Hallem, 2012). Although the functions of some oxylipins from some parasites are known, considering the diversity of parasite species and the breadth of their host taxa, the functions of oxylipins in host-parasite interactions are largely unexplored (Noverr et al., 2003; Chaisson and Hallem, 2012).

Oxylipins are released by all biota transported within their environment, received and perceived by another individual, leading to possible changes in behavior depending on the receiver's state or species (Baldwin et al., 2006; Fink, 2007). The reception of these chemical cues may trigger chemokinesis and chemiotaxis in a wide diversity of species in response to the presence of a specific cocktail of cues and play an important role in species interactions within aquatic systems (de Petrocellis and di Marzo, 1994; Fink, 2007; Pohnert et al., 2007; Poulson et al., 2009; Brönmark and Hansson, 2012). For example, oxylipin cocktails released from a benthic diatom (Achnanthes biasolettiana) were attractive to the Wandering snail (Radix ovata) (Fink et al., 2006a). Yet, another diatom species (Gomphonema parvulum) was not attractive to the snail, demonstrating that differences in oxylipin cocktails between species were detected and elicited a differential response from the snail (Fink et al., 2006a,b; Fink, 2007).

Preliminary research suggests that oxylipins may strongly influence ecosystem processes and fine-scale community structure, through structuring planktonic food webs, and influencing patchiness of consumers within ecosystems (Pohnert et al., 2007; Moelzner and Fink, 2015a; Saha et al., 2019). Gastropods respond to oxylipin cues from food sources and shift their behavior in response to food resource quality (Moelzner and Fink, 2014, 2015a). As snails actively grazed upon food sources, chemicals released by the snail and its prey provide information about the quality and types of food resources in the environment (Moelzner and Fink, 2015b). The perception of these cues is a potential mechanism behind the patchy distribution of herbivores within communities (Moelzner and Fink, 2015a).

Parasites themselves use chemoperception of host-generated oxylipins to facilitate transmission to hosts (Daugschies and Joachim, 2000; Noverr et al., 2003; Chaisson and Hallem, 2012). For example, host-seeking by sea lice (Lepeophtheirus salmonis) is mediated by the parasite's attraction to isophorone, an oxylipin expressed by salmon hosts (Salmo salar and Scophthalmus maximus) (Ingvarsdóttir et al., 2002; Bailey et al., 2006). Similarly, aquatic transmission of larval blood flukes (Schistosoma spp.) to invertebrate (miracidia stage) and vertebrate (cercariae stage) hosts is increased in the presence of particular host-derived oxylipins (Fusco et al., 1986; Allan et al., 2009). In this system, not only do a larger percentage of cercarial blood flukes penetrate 
hosts, but the parasite also alters the biosynthesis of some of their own oxylipins (Fusco et al., 1986; Nevhutalu et al., 1993; Chaisson and Hallem, 2012). If the host's behavior is affected by this change in the parasite oxylipins, this could be an instance where oxylipins mediate NCEs in host-parasite interactions. But, despite the potential importance of oxylipins in structuring community interactions, oxylipin cocktails are not well studied in aquatic systems and most of this research has focused on twoway interactions between free-living species (Fink, 2007; Saha et al., 2019). Given the preponderance of parasites in aquatic systems, more work is needed to understand the key molecules in chemoperception by parasites, whether parasites alter their oxylipins after receiving host cues, and whether these in changes parasite cues induce changes in community interactions (Fink, 2007; Pohnert et al., 2007; Sures et al., 2017).

\section{PARASITE IMPACTS ON CHEMICAL COMMUNICATION}

Parasitism of aquatic hosts can lead to behavioral and physiological changes in the host, including the alteration of feeding rates, stress response, survival, and competition (Park, 1948; Rivero and Ferguson, 2003; Bedhomme et al., 2005; Lefèvre et al., 2009; Friesen et al., 2020). Host behavioral modifications can include changes in activity levels, aggression, boldness, microhabitat use, and attraction of uninfected host species (Kunz and Pung, 2004; Mikheev et al., 2010; Reisinger et al., 2015; Friesen et al., 2018; Eliuk et al., 2020). It is often suggested that chemical cues may be mediating these types of behaviors and interactions albeit through indirect evidence (e.g., Rohr et al., 2009; Eliuk et al., 2020). As a result, our understanding of how parasites may impact chemical communication in an ecological context is not well understood.

Although a few hypotheses have been proposed to explain changes in host behavior, the potential mechanisms, including the role of chemical communication, are rarely explored (Poulin, 2010; Heil, 2016; Herbison et al., 2018). One hypothesis proposes that parasites may cause pathology to their host, and the side effects or byproducts of this pathology may lead to changes in host behavior and physiology (Pohnert, 2002; Poulin, 2010; Heil, 2016). Oxylipins may be one potential mechanism for this hypothesis as oxylipins are released by some hosts in response to an attack, or tissue damage (Morishima et al., 1997; Funk, 2001). Wound-activated lipases can start to liberate oxylipins as disease progresses and even mediate symptoms (Pohnert, 2002; D'Ippolito et al., 2004; Maibam et al., 2014). During this process, the oxylipin cocktail released by the host may include these novel or upregulated oxylipins, altering its composition and thereby affecting interactions relying on this chemical communication.

An alternative hypothesis proposes that an adaptive response to infection may be a mechanism for alterations in host behavior due to parasites (Poulin, 2010). The host may change its behavior or physiology in order to either mitigate the consequences of this infection or to be rid of the infection or infestation all together (Poulin, 2010; Heil, 2016). Oxylipins are known to modulate the immune response of insects and plants in response to pathogens and predation in a variety of ecosystems (StanleySamuelson et al., 1991; Noverr et al., 2003; Pozo et al., 2004; Pieterse and Dicke, 2007). Hosts may produce different amounts or combinations of oxylipins in attempts to remove infection (Noverr et al., 2003; Heil, 2016).

Finally, parasites may directly manipulate their hosts through biochemical interference (Poulin, 2010). Many parasite species are known to produce a variety of oxylipins (Noverr et al., 2003; Chaisson and Hallem, 2012). Parasites may use oxylipins to their advantage and produce oxylipins that modulate host immune systems as a way to protect themselves (Noverr et al., 2003). Parasites have evolved mechanisms to suppress the host defense response by interfering with key pathway regulators (Angeli et al., 2001; Pozo et al., 2004). We suggest that altering oxylipins released by the host or the release of oxylipins by the parasite are adaptive avenues by which the parasite could directly modify their host behavior in a manner that would benefit the parasite, such as increased transmission.

Parasite modification of chemical cues released by their host, through any of the mechanisms described above, will affect interactions and other physiological processes involving these cues. Oxylipins have crucial hormone-like functions within species and play roles in secondary metabolite biosynthesis (Holighaus and Rohlfs, 2019). If parasites release novel or higher amounts of oxylipins than their hosts or induce changes in the production of oxylipins by their host, this may induce behavioral changes in their host, such as boldness and feeding rates, as many oxylipins are well-known as extracellular signaling molecules (Noverr et al., 2003; Gabbs et al., 2015). Additionally, if an altered oxylipin cocktail contains novel or an increased amount of oxylipins that induce chemotaxis by conspecifics (e.g., oxylipins used in mate finding, prey seeking), the change in cocktail may lead to attraction of novel hosts (including predators) increasing the chances of successful transmission.

\section{NON-CONSUMPTIVE EFFECTS OF PARASITISM MEDIATED BY ALTERED CUES}

To avoid parasitism, host species may adjust their behavior and physiology (Rohr et al., 2009; Horn et al., 2020). These NCEs of parasites are an ecological consequence of novel host responses to infection risk (Rohr et al., 2009; Koprivnikar and Penalva, 2015). The importance of NCEs of parasites and the role of chemical cues in these interactions has been recognized but much is still not understood (Rohr et al., 2009). For example, tadpoles (Bufo americanus) exhibited avoidance behavior and elevated activity in response to chemical cues produced by a snail (Planorbella trivolvis) shedding Echinostoma trivolvis cercariae (Rohr et al., 2009). A potential mechanism for these effects is manipulation of oxylipin cocktails by the parasite, by altering the production of host oxylipins or releasing oxylipins of its own.

If parasites alter the oxylipin cocktail of their host, parasites can alter the signaling web. Other individuals within the community may receive different signals and as a result alter their behavior because of the modifications in the oxylipin 
cocktails (Vos et al., 2006). In some cases, other conspecifics and heterospecifics may have evolved to respond to these changes, like responses to alarm cues, by reacting to an imminent risk of becoming infected themselves. Alterations could include an uninfected individual actively changing phenotypic traits, like its behavior, physiology, or habitat use to avoid becoming infected (Hill and Weissburg, 2013). A naïve host may prime their immune system in response to the perceived risk of becoming infected, which is likely to be energetically costly (McPherson et al., 2018). The defense priming of other naïve species may have additional consequences to the transmission success of other parasites within the ecosystem, which in turn may have cascading impacts on the entire community (Friesen et al., 2020). As a defense to the perceived risk, individuals may spend time trying to avoid the threat, but in turn this may increase their vulnerability to predation by reducing time spent on effective defenses and foraging, reducing their ability to compete for resources, and reducing energy available to reproduce, develop and/or grow (Koprivnikar and Penalva, 2015). These altered cues within aquatic signaling webs could also provide one mechanism driving the "ecology of fear" in these communities (Buck et al., 2018; Weinstein et al., 2018; Zanette and Clinchy, 2019). Further, modified cues may ultimately lead to altered species abundance and distribution, and competition resulting in potentially dramatic impacts on ecosystems (Thiemann and Wassersug, 2000; Marino et al., 2014; Buck et al., 2018; Horn et al., 2020).

\section{FUTURE DIRECTIONS AND MODEL SYSTEMS}

Due to our limited understanding of the extent that oxylipins mediate interactions, including NCEs, many effects of oxylipin modification remain speculative and require further research. Gastropods and trematode parasites are ubiquitous, have essential functional roles, and their interactions are fundamental

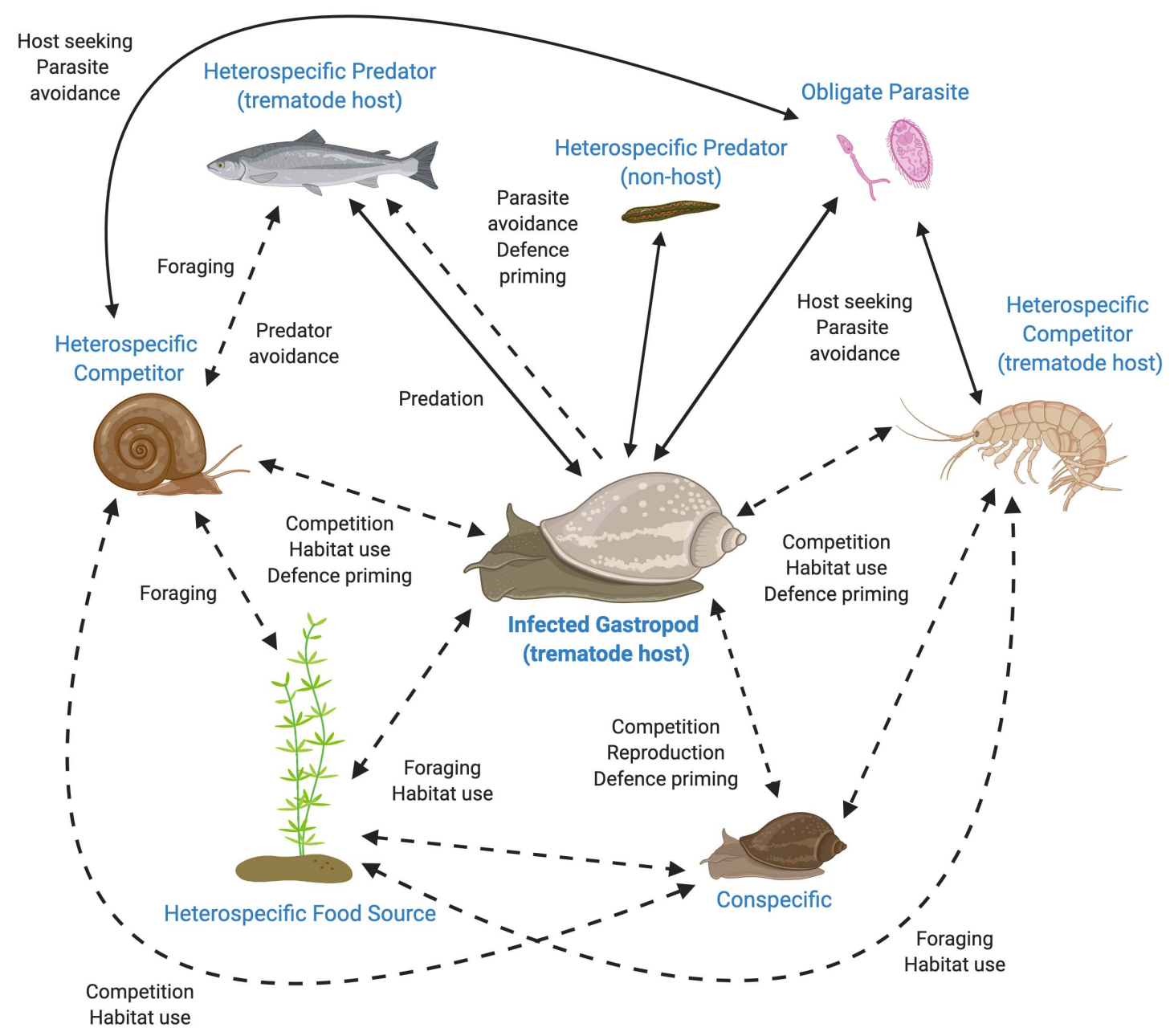

FIGURE 1 | Interactions in a freshwater community potentially mediated by chemical cues originating from a trematode-infected gastropod. Many of these interactions include non-consumptive effects of parasites that may be mediated by oxylipins [Dotted lines (and labels in bold)]. All interactions would be impacted by any change in the gastropod's oxylipins, which would then have far reaching consequences for the surrounding community. Figure created with BioRender.com. 
to community dynamics within aquatic ecosystems (Hawkins and Furnish, 1987; Fink et al., 2006a; Wojdak and Mittelbach, 2007; Strong et al., 2008). Thus, they present promising systems to test hypotheses related to the role of oxylipins in mediating NCEs of parasites. Gastropods serve as intermediate hosts to trematode parasites, which infect a wide variety of other host species to complete their life cycles. As trematodes penetrate, migrate, develop, and feed in gastropods, the oxylipin cocktails emitted by these hosts may change. For example, as redial stages of trematodes consume gonad tissue, oxylipins important for reproductive activities of gastropods may be reduced or eliminated. Gastropod hosts may also alter their oxylipin cocktail to increase their reproductive output in order to mitigate the costs of infection, such as a shortened life span or castration (Sorensen and Minchella, 2001).

As gastropods and trematodes are known to both produce and respond to oxylipins and represent a crucial interaction within aquatic communities, these model systems are ideal for testing the role of oxylipins in mediating NCEs of parasites within aquatic environments (see Figure 1). Currently, the chemical cues of schistosome and echinostome trematodes have received the most attention (e.g., Haas et al., 1995; Noverr et al., 2003; Chaisson and Hallem, 2012; Langeloh and Seppälä, 2018). These trematodes could be further explored to test if the behavior or physiology (e.g., immune function) of their conspecific or heterospecific snail hosts are altered in response to exposure to the chemical cocktails produced by infected snails compared to cocktails produced by uninfected snails, or trematodes themselves (Figure 1; Rohr et al., 2009; Langeloh and Seppälä, 2018; Eliuk et al., 2020). Oxylipin cocktails produced by infected snails can be characterized, isolated and used to directly test the role of chemical signals in mediating NCEs of parasites. Further, exposure to these modified chemical cocktails alone could be used to test differences in behavior by other snails and other aquatic community members, such as their foraging time, habitat use, reproductive output, competition, and the ability to evade predators. The generality and strength of alterations to oxylipins in response to infection and their consequences in mediating interactions could be assessed by testing across the diversity of trematodes and snail hosts, between hosts within a life cycle, and according to host-specificity of the trematode. Further, the dynamic nature of chemical communication in snail trematode-systems can be investigated in different contexts such as in controlled laboratory, semi-natural, and natural conditions.

As oxylipins are impacted by shifts in temperature, we can test whether signaling webs and pathway crosstalk involving gastropods and trematodes are being affected by climate change. Emerging research has demonstrated that alterations in oxylipin cues change the outcome of predator-prey interactions (Zupo et al., 2015). Many non-target individuals will be receiving and

\section{REFERENCES}

Ali, S. F., Joachim, A., and Daugschies, A. (1999). Eicosanoid production by adult Fasciola hepatica and plasma eicosanoid patterns during fasciolosis in sheep. Int. J. Parasitol. 29, 743-748. doi: 10.1016/S0020-7519(99)00020-X responding to parasite-modified cues within the signaling web, which may lead to unpredictable changes to the community (e.g., freshwater fish, Fisher et al., 2006). Given the indirect evidence available, we think it is reasonable to suggest variation in parasite diversity and abundance, which ultimately alters the signaling web of a community, may have similarly dramatic impacts on aquatic communities by mediating NCEs of parasites within the community.

In addition, as trematode parasites are ubiquitous throughout aquatic ecosystems and often dominate the biomass of communities, the alteration of chemical cues, like oxylipin cocktails, through parasite infection, may have far reaching effects, modifying the signaling web and affecting pathway crosstalk (Mitchell, 2003; Kuris et al., 2008; Lagrue and Poulin, 2016; Paseka, 2017). Because gastropod-trematode systems can be readily studied in nature and the lab, the impacts of NCEs of parasites mediated by chemical cues can be explored in a variety of contexts. They provide an ideal opportunity to investigate the role of chemical cues in influencing ecological interactions (from individual to community level) and ecosystem processes.

\section{DATA AVAILABILITY STATEMENT}

The original contributions presented in the study are included in the article/supplementary material, further inquiries can be directed to the corresponding author/s.

\section{AUTHOR CONTRIBUTIONS}

OF and JD developed and wrote the manuscript. Both authors contributed to the manuscript and approved the submitted version.

\section{FUNDING}

Funding for OF was provided by the Weston Family Awards in Northern Research Postdoctoral Fellowship. Funding for JD was through a Natural Sciences and Engineering Research Council of Canada (NSERC) Discovery grant.

\section{ACKNOWLEDGMENTS}

We thank Janet Koprivnikar for the invitation (on behalf of the other topic editors) to contribute to this Research Topic. We also thank members of the Detwiler Laboratory for feedback and remarks on a draft of this manuscript, and Jake Stout for initially inspiring our research direction.

Allan, F., Rollinson, D., Smith, J. E., and Dunn, A. M. (2009). Host choice and penetration by Schistosoma haematobium miracidia. J. Helminthol. 83, 33-38. doi: 10.1017/S0022149X08073628

Angeli, V., Faveeuw, C., Roye, O., Fontaine, J., Teissier, E., Capron, A., et al. (2001). Role of the parasite-derived prostaglandin D2 in the inhibition of epidermal 
Langerhans cell migration during schistosomiasis infection. J. Exp. Med. 193, 1135-1147. doi: 10.1084/jem.193.10.1135

Bailey, R. J. E., Birkett, M. A., Ingvarsdóttir, A., Mordue, A. J., Mordue, W., O’Shea, B., et al. (2006). The role of semiochemicals in host location and non-host avoidance by salmon louse (Lepeophtheirus salmonis) copepodids. Can. J. Fish. Aquat. Sci. 63, 448-456. doi: 10.1139/f05-231

Baldwin, I. T., Halitschke, R., Paschold, A., Von Dahl, C. C., and Preston, C. A. (2006). Volatile signaling in plant-plant interactions: "Talking trees" in the genomics era. Science 311, 812-815. doi: 10.1126/science.1118446

Bedhomme, S., Agnew, P., Vital, Y., Sidobre, C., and Michalakis, Y. (2005). Prevalence-dependent costs of parasite virulence. PLoS Biol. 3:e262. doi: 10. 1371/journal.pbio.0030262

Brönmark, C., and Hansson, L.-A. (eds) (2012). Chemical Ecology in Aquatic Systems. Oxford: Oxford University Press.

Brönmark, C., and Hansson, L.-A. (2000). Chemical communication in aquatic systems: an introduction. Oikos 88, 103-109. doi: 10.1034/j.1600-0706.2000. 880112.x

Buck, J. C., Weinstein, S. B., and Young, H. S. (2018). Ecological and evolutionary consequences of parasite avoidance. Trends Ecol. Evol. 33, 619-632. doi: 10. 1016/j.tree.2018.05.001

Burks, R. L., and Lodge, D. M. (2002). Cued in: advances and opportunities in freshwater chemical ecology. J. Chem. Ecol. 28, 1901-1917. doi: 10.1023/A: 1020785525081

Caldwell, G. S. (2009). The influence of bioactive oxylipins from marine diatoms on invertebrate reproduction and development. Mar. Drugs 7, 367-400. doi: 10.3390/md7030367

Chaisson, K. E., and Hallem, E. A. (2012). Chemosensory behaviours of parasites. Trends Parasitol. 28, 427-436. doi: 10.1016/j.pt.2012.07.004.Chemosensory

Daugschies, A., and Joachim, A. (2000). Eicosanoids in parasites and parasitic infections. Adv. Parasitol. 46, 181-240. doi: 10.1016/s0065-308x (00) 46009-4

de Petrocellis, L., and di Marzo, V. (1994). Aquatic invertebrates open up new perspectives in eicosanoid research: biosynthesis and bioactivity. Prostaglandins Leukot. Essent. Fat. Acids 51, 215-229. doi: 10.1016/0952-3278(94)90183-X

D’Ippolito, G., Tucci, S., Cutignano, A., Romano, G., Cimino, G., Miralto, A., et al. (2004). The role of complex lipids in the synthesis of bioactive aldehydes of the marine diatom Skeletonema costatum. Biochim. Biophys. Acta Mol. Cell Biol. Lipids 1686, 100-107. doi: 10.1016/j.bbalip.2004.09.002

Dicke, M., and Sabelis, M. W. (1988). Infochemical terminology: based on costbenefit analysis rather than origin of compounds? Funct. Ecol. 2, 131-139. doi: $10.2307 / 2389687$

Eliuk, L. K., Brown, S., Wyeth, R. C., and Detwiler, J. T. (2020). Parasite-modified behaviour in non-trophic transmission: trematode parasitism increases the attraction between snail intermediate hosts. Can. J. Zool. 98, 417-424. doi: 10.1139/cjz-2019-0251

Ferrari, M. C. O., Wisenden, B. D., and Chivers, D. P. (2010). Chemical ecology of predator-prey interactions in aquatic ecosystems: a review and prospectus. Can. J. Zool. 88, 698-724. doi: 10.1139/Z10-029

Fink, P. (2007). Ecological functions of volatile organic compounds in aquatic systems. Mar. Freshw. Behav. Physiol. 40, 155-168. doi: 10.1080/ 10236240701602218

Fink, P., Von Elert, E., and Jüttner, F. (2006a). Oxylipins from freshwater diatoms act as attractants for a benthic herbivore. Arch. Hydrobiol. 167, 561-574. doi: 10.1127/0003-9136/2006/0167-0561

Fink, P., Von Elert, E., and Jüttner, F. (2006b). Volatile foraging kairomones in the littoral zone: attraction of an herbivorous freshwater gastropod to algal odors. J. Chem. Ecol. 32, 1867-1881. doi: 10.1007/s10886-0069115-y

Fisher, H. S., Wong, B. B. M., and Rosenthal, G. G. (2006). Alteration of the chemical environment disrupts communication in a freshwater fish. Proc. $R$. Soc. B Biol. Sci. 273, 1187-1193. doi: 10.1098/rspb.2005.3406

Friesen, O. C., Goellner, S., Poulin, R., and Lagrue, C. (2020). Parasites shape community structure and dynamics in freshwater crustaceans. Parasitology 147 , 182-193. doi: 10.1017/S0031182019001483

Friesen, O. C., Poulin, R., and Lagrue, C. (2018). Parasite-mediated microhabitat segregation between congeneric hosts. Biol. Lett. 14:20170671. doi: 10.1098/rsbl. 2017.0671
Funk, C. D. (2001). Prostaglandins and leukotrienes: advances in eicosanoid biology. Science 294, 1871-1875. doi: 10.1126/science.294.5548.1871

Fusco, A. C., Salafsky, B., and Delbrook, K. (1986). Schistosoma mansoni: production of cercarial eicosanoids as correlates of penetration and transformation. J. Parasitol. 72, 397-404. doi: 10.2307/3281679

Gabbs, M., Leng, S., Devassy, J. G., and Aukema, H. M. (2015). Advances in our understanding of oxylipins. Am. Soc. Nutr. 6, 513-540. doi: 10.3945/an.114. 007732.PUFAs

Haas, W., Haberl, B., Kalbe, M., and Körner, M. (1995). Snail-host-finding by miracidia and cercariae: chemical host cues. Parasitol. Today 11, 468-472. doi: 10.1016/0169-4758(95)80066-2

Hawkins, C. P., and Furnish, J. K. (1987). Are snails important competitors in stream ecosystems? Oikos 49, 209-220. doi: 10.2307/3566028

Heil, M. (2016). Host manipulation by parasites: cases, patterns, and remaining doubts. Front. Ecol. Evol. 4:80. doi: 10.3389/fevo.2016.00080

Herbison, R., Lagrue, C., and Poulin, R. (2018). The missing link in parasite manipulation of host behaviour. Parasit. Vectors 11:222. doi: 10.1186/s13071018-2805-9

Hermann, S. L., and Landis, D. A. (2017). Scaling up our understanding of nonconsumptive effects in insect systems. Curr. Opin. Insect Sci. 20, 54-60. doi: 10.1016/j.cois.2017.03.010

Hill, J. M., and Weissburg, M. J. (2013). Predator biomass determines the magnitude of non-consumptive effects (NCEs) in both laboratory and field environments. Oecologia 172, 79-91. doi: 10.1007/s00442-012-2488-4

Holighaus, G., and Rohlfs, M. (2019). Volatile and non-volatile fungal oxylipins in fungus-invertebrate interactions. Fungal Ecol. 38, 28-36. doi: 10.1016/j.funeco. 2018.09.005

Horn, C. J., Mierzejewski, M. K., Elahi, M. E., and Luong, L. T. (2020). Extending the ecology of fear: parasite-mediated sexual selection drives host response to parasites. Physiol. Behav. 224:113041. doi: 10.1016/j.physbeh.2020.113041

Ingvarsdóttir, A., Birkett, M. A., Duce, I., Genna, R. L., Mordue, W., Pickett, J. A., et al. (2002). Semiochemical strategies for sea louse control: host location cues. Pest Manag. Sci. 58, 537-545. doi: 10.1002/ps.510

Kats, L. B., and Dill, L. M. (1998). The scent of death: chemosensory assessment of predation risk by prey animals. Ecoscience 5, 361-394. doi: 10.1080/11956860. 1998.11682468

Kaupp, U. B., Hildebrand, E., and Weyand, I. (2006). Sperm chemotaxis in marine invertebrates - molecules and mechanisms. J. Cell. Physiol. 208, 487-494. doi: $10.1002 / j c p$

Kergunteuil, A., Humair, L., Maire, A. L., Moreno-Aguilar, M. F., Godschalx, A., Catalán, P., et al. (2020). Tritrophic interactions follow phylogenetic escalation and climatic adaptation. Sci. Rep. 10:2074. doi: 10.1038/s41598-020-59068-2

Kita, M., Kitamura, M., and Uemura, D. (2010). "Pheromones of marine invertebrates and algae," in Comprehensive Natural Products II Chem. Biol, Vol. 4, ed. K. Mori (Oxford: Elsevier), 263-281. doi: 10.1016/b978-008045382-8. 00097-6

Koprivnikar, J., and Penalva, L. (2015). Lesser of two evils? Foraging choices in response to threats of predation and parasitism. PLoS One 10:e0116569. doi: 10.1371/journal.pone.0116569

Kubata, B. K., Duszenko, M., Kabututu, Z., Rawer, M., Szallies, A., Fujimori, $\mathrm{K}$., et al. (2000). Identification of a novel prostaglandin $F_{2 \alpha}$ synthase in Trypanosoma brucei. J. Exp. Med. 192, 1327-1337. doi: 10.1084/jem.192. 9.1327

Kubata, B. K., Eguchi, N., Urade, Y., Yamashita, K., Mitamura, T., Tai, K., et al. (1998). Plasmodium falciparum produces prostaglandins that are pyrogenic, somnogenic, and immunosuppressive substances in humans. J. Exp. Med. 188, 1197-1202. doi: 10.1084/jem.188.6.1197

Kunz, A. K., and Pung, O. J. (2004). Effects of Microphallus turgidus (Trematoda: Microphallidae) on the predation, behavior, and swimming stamina of the grass shrimp Palaemonetes pugio. J. Parasitol. 90, 441-445. doi: 10.1645/GE183R

Kuris, A. M., Hechinger, R. F., Shaw, J. C., Whitney, K. L., Aguirre-Macedo, L., Boch, C. A., et al. (2008). Ecosystem energetic implications of parasite and free-living biomass in three estuaries. Nature 454, 515-518. doi: 10.1038/ nature 06970

Lagrue, C., and Poulin, R. (2016). The scaling of parasite biomass with host biomass in lake ecosystems: are parasites limited 
by host resources? Ecography 39, 507-514. doi: 10.1111/ecog. 01720

Langeloh, L., and Seppälä, O. (2018). Relative importance of chemical attractiveness to parasites for susceptibility to trematode infection. Ecol. Evol. 8, 8921-8929. doi: 10.1002/ece3.4386

Lefèvre, T., Lebarbenchon, C., Gauthier-Clerc, M., Missé, D., Poulin, R., and Thomas, F. (2009). The ecological significance of manipulative parasites. Trends Ecol. Evol. 24, 41-48. doi: 10.1016/j.tree.2008.08.007

Liu, L. X., and Weller, P. F. (1992). Intravascular filarial parasites inhibit platelet aggregation: role of parasite-derived prostanoids. J. Clin. Invest. 89, 1113-1120. doi: 10.1172/JCI115691

Maibam, C., Fink, P., Romano, G., Buia, M. C., Gambi, M. C., Scipione, M. B., et al. (2014). Relevance of wound-activated compounds produced by diatoms as toxins and infochemicals for benthic invertebrates. Mar. Biol. 161, 1639-1652. doi: 10.1007/s00227-014-2448-0

Marino, J. A., Holland, M. P., and Middlemis Maher, J. (2014). Predators and trematode parasites jointly affect larval anuran functional traits and corticosterone levels. Oikos 123, 451-460. doi: 10.1111/j.1600-0706.2013. 00896.x

Martin, L. B., Addison, B. A., Bean, A. G. D., Buchanan, K. L., Crino, O. L., Eastwood, J. R., et al. (2019). Extreme competence: keystone hosts of infections. Trends Ecol. Evol. 34, 303-314. doi: 10.1016/j.tree.2018.12.009

McPherson, O. G., Friesen, O. C., Selbach, C., and Poulin, R. (2018). Prior infections or defence priming: what determines the risk of trematode infections in amphipod hosts? Parasitol. Res. 117, 1915-1923. doi: 10.1007/s00436-018$5885-8$

Metcalf, R. L., and Kogan, M. (1987). Plant volatiles as insect attractants. Crit. Rev. Plant Sci. 5, 251-301. doi: 10.1080/07352688709382242

Mikheev, V. N., Pasternak, A. F., Taskinen, J., and Valtonen, E. T. (2010). Parasiteinduced aggression and impaired contest ability in a fish host. Parasit. Vectors 3:17. doi: 10.1186/1756-3305-3-17

Mitchell, C. E. (2003). Trophic control of grassland production and biomass by pathogens. Ecol. Lett. 6, 147-155. doi: 10.1046/j.1461-0248.2003.00408.x

Moelzner, J., and Fink, P. (2014). The smell of good food: volatile infochemicals as resource quality indicators. J. Anim. Ecol. 83, 1007-1014. doi: 10.1111/13652656.12220

Moelzner, J., and Fink, P. (2015a). Consumer patchiness explained by volatile infochemicals in a freshwater ecosystem. Ecosphere 6, 1-15. doi: 10.1890/ES1400246.1

Moelzner, J., and Fink, P. (2015b). Gastropod grazing on a benthic alga leads to liberation of food-finding infochemicals. Oikos 124, 1603-1608. doi: 10.1111/ oik.02069

Morishima, I., Yamano, Y., Inoue, K., and Matsuo, N. (1997). Eicosanoids mediate induction of immune genes in the fat body of the silkworm, Bombyx mori. FEBS Lett. 419, 83-86. doi: 10.1016/S0014-5793(97)01418-X

Nevhutalu, P. A., Salafsky, B., Haas, W., and Conway, T. (1993). Schistosoma mansoni and Trichobilharzia ocellata: comparison of secreted cercarial eicosanoids. J. Parasitol. 79, 130-133. doi: 10.2307/3283293

Noverr, M. C., Erb-Downward, J. R., and Huffnagle, G. B. (2003). Production of eicosanoids and other oxylipins by pathogenic eukaryotic microbes. Clin. Microbiol. Rev. 16, 517-533. doi: 10.1128/CMR.16.3.517-533.2003

Park, T. (1948). Interspecies competition in populations of Tribolium confusum Duval and Tribolium castaneum Herbst. Ecol. Monogr. 18, 265-307. doi: 10. 2307/1948641

Paseka, R. E. (2017). Low parasite biomass in oligotrophic streams differs from previous estimates in aquatic ecosystems. Freshw. Sci. 36, 377-386. doi: 10.1086/ 691471

Pieterse, C. M. J., and Dicke, M. (2007). Plant interactions with microbes and insects: from molecular mechanisms to ecology. Trends Plant Sci. 12, 564-569. doi: $10.1016 /$ j.tplants.2007.09.004

Pohnert, G. (2002). Phospholipase $\mathrm{A}_{2}$ activity triggers the wound-activated chemical defense in the diatom Thalassiosira rotula. Plant Physiol. 129, 103-111. doi: 10.1104/pp.010974

Pohnert, G., Steinke, M., and Tollrian, R. (2007). Chemical cues, defence metabolites and the shaping of pelagic interspecific interactions. Trends Ecol. Evol. 22, 198-204. doi: 10.1016/j.tree.2007. 01.005
Poulin, R. (2010). Parasite Manipulation of Host Behavior: An Update and Frequently Asked Questions, 1st Edn. Amsterdam: Elsevier Inc. doi: 10.1242/ jeb.073353

Poulson, K. L., Sieg, R. D., and Kubanek, J. (2009). Chemical ecology of the marine plankton. Nat. Prod. Rep. 26, 729-745. doi: 10.1039/b806214p

Pozo, M. J., Van Loon, L. C., and Pieterse, C. M. J. (2004). Jasmonates - signals in plant-microbe interactions. J. Plant Growth Regul. 23, 211-222. doi: 10.1007/ s00344-004-0031-5

Reisinger, L. S., Petersen, I., Hing, J. S., Davila, R. L., and Lodge, D. M. (2015). Infection with a trematode parasite differentially alters competitive interactions and antipredator behaviour in native and invasive crayfish. Freshw. Biol. 60, 1581-1595. doi: 10.1111/fwb. 12590

Rivero, A., and Ferguson, H. M. (2003). The energetic budget of Anopheles stephensi infected with Plasmodium chabaudi: is energy depletion a mechanism for virulence? Proc. R. Soc. B Biol. Sci. 270, 1365-1371. doi: 10.1098/rspb.2003. 2389

Rohr, J. R., Swan, A., Raffel, T. R., and Hudson, P. J. (2009). Parasites, infodisruption, and the ecology of fear. Oecologia 159, 447-454. doi: 10.1007/ s00442-008-1208-6

Saha, M., Berdalet, E., Carotenuto, Y., Fink, P., Harder, T., John, U., et al. (2019). Using chemical language to shape future marine health. Front. Ecol. Environ. 17:530-537. doi: 10.1002/fee.2113

Schultz, J. C., and Appel, H. M. (2004). Cross-kingdom cross-talk: hormones shared by plants and their insect herbivores. Ecology 85, 70-77. doi: 10.1890/ 02-0704

Sorensen, R. E., and Minchella, D. J. (2001). Snail-trematode life history interactions: past trends and future directions. Parasitology 123, 3-18. doi: $10.1017 / \mathrm{s} 0031182001007843$

Stanley, D. W. (2014). "Eicosanoids in invertebrate immunity," in Eicosanoids in Invertebrate Signal Transduction Systems, ed. D. W. Stanley (Princeton, NJ: Princeton University Press), 109-148.

Stanley-Samuelson, D. W. (1994). The biological significance of prostaglandines and related eicosanoids in invertebrates. Am. Zool. 34, 589-598. doi: 10.1093/ $\mathrm{icb} / 34.6 .589$

Stanley-Samuelson, D. W., Jensen, E., Nickerson, K. W., Tiebel, K., Ogg, C. L., and Howard, R. W. (1991). Insect immune response to bacterial infection is mediated by eicosanoids. Proc. Natl. Acad. Sci. U.S.A. 88, 1064-1068. doi: 10.1073/pnas.88.3.1064

Strong, E. E., Gargominy, O., Ponder, W. F., and Bouchet, P. (2008). Global diversity of gastropods (Gastropoda; Mollusca) in freshwater. Hydrobiologia 595, 149-166. doi: 10.1007/s10750-0079012-6

Sures, B., Nachev, M., Pahl, M., Grabner, D., and Selbach, C. (2017). Parasites as drivers of key processes in aquatic ecosystems: facts and future directions. Exp. Parasitol. 180, 141-147. doi: 10.1016/j.exppara.2017.03.011

Thiemann, G. W., and Wassersug, R. J. (2000). Patterns and consequences of behavioural responses to predators and parasites in Rana tadpoles. Biol. J. Linn. Soc. 71, 513-528. doi: 10.1006/bijl.2000.0459

van Poecke, R. M. P., and Dicke, M. (2004). Indirect defence of plants against herbivores: using Arabidopsis thaliana as a model plant. Plant Biol. 6, 387-401. doi: 10.1055/s-2004-820887

Vos, M., Vet, L. E. M., Wäckers, F. L., Middelburg, J. J., Van Der Putten, W. H., Mooij, W. M., et al. (2006). Infochemicals structure marine, terrestrial and freshwater food webs: implications for ecological informatics. Ecol. Inform. 1, 23-32. doi: 10.1016/j.ecoinf.2005. 06.001

Weinstein, S. B., Moura, C. W., Mendez, J. F., and Lafferty, K. D. (2018). Fear of feces? Tradeoffs between disease risk and foraging drive animal activity around raccoon latrines. Oikos 127, 927-934. doi: 10.1111/oik.04866

Weissburg, M. J., and Beauvais, J. (2015). The smell of success: the amount of prey consumed by predators determines the strength and range of cascading non-consumptive effects. PeerJ 3:e1426. doi: 10.7717/peerj. 1426

Wendel, T., and Jüttner, F. (1996). Lipoxygenase-mediated formation of hydrocarbons and unsaturated aldehydes in freshwater diatoms. Phytochemistry 41, 1445-1449. doi: 10.1016/0031-9422(95)0 0828-4 
Wojdak, J. M., and Mittelbach, G. G. (2007). Consequences of niche overlap for ecosystem functioning: an experimental test with pond grazers. Ecology 88, 2072-2083. doi: 10.1890/060651.1

Zanette, L. Y., and Clinchy, M. (2019). Ecology of fear. Curr. Biol. 29, R309-R313. doi: 10.1016/j.cub.2019.02.042

Zupo, V., Maibam, C., Buia, M. C., Gambi, M. C., Patti, F. P., Scipione, M. B., et al. (2015). Chemoreception of the seagrass Posidonia oceanica by benthic invertebrates is altered by seawater acidification. J. Chem. Ecol. 41, 766-779. doi: 10.1007/s10886-015-0610-x
Conflict of Interest: The authors declare that the research was conducted in the absence of any commercial or financial relationships that could be construed as a potential conflict of interest.

Copyright (c) 2021 Friesen and Detwiler. This is an open-access article distributed under the terms of the Creative Commons Attribution License (CC BY). The use, distribution or reproduction in other forums is permitted, provided the original author(s) and the copyright owner(s) are credited and that the original publication in this journal is cited, in accordance with accepted academic practice. No use, distribution or reproduction is permitted which does not comply with these terms. 